\title{
The Chemokine Stromal Cell-Derived Factor-1 Regulates GABAergic Inputs to Neural Progenitors in the Postnatal Dentate Gyrus
}

\author{
Bula J. Bhattacharyya, ${ }^{1}$ Ghazal Banisadr, ${ }^{1}$ Hosung Jung, ${ }^{1}$ Dongjun Ren, ${ }^{1}$ Darran G. Cronshaw, ${ }^{2}$ Yongrui Zou, ${ }^{2}$ and \\ Richard J. Miller ${ }^{1}$ \\ 'Department of Molecular Pharmacology and Biological Chemistry, Feinberg School of Medicine, Northwestern University, Chicago, Illinois 60611, and \\ 2Department of Microbiology, College of Physicians and Surgeons, Columbia University, New York, New York 10032
}

\begin{abstract}
Stromal cell-derived factor-1 (SDF-1) and its receptor CXC chemokine receptor 4 (CXCR4) are important regulators of the development of the dentate gyrus (DG). Both SDF-1 and CXCR4 are also highly expressed in the adult DG. We observed that CXCR4 receptors were expressed by dividing neural progenitor cells located in the subgranular zone (SGZ) as well as their derivatives including doublecortinexpressing neuroblasts and immature granule cells. SDF-1 was located in DG neurons and in endothelial cells associated with DG blood vessels. SDF-1-expressing neurons included parvalbumin-containing GABAergic interneurons known as basket cells. Using transgenic mice expressing an SDF-1-mRFP1 (monomeric red fluorescence protein 1) fusion protein we observed that SDF-1 was localized in synaptic vesicles in the terminals of basket cells together with GABA-containing vesicles. These terminals were often observed to be in close proximity to dividing nestin-expressing neural progenitors in the SGZ. Electrophysiological recordings from slices of the DG demonstrated that neural progenitors received both tonic and phasic GABAergic inputs and that SDF-1 enhanced GABAergic transmission, probably by a postsynaptic mechanism. We also demonstrated that, like GABA, SDF-1 was tonically released in the DG and that GABAergic transmission was partially dependent on coreleased SDF-1. These data demonstrate that SDF-1 plays a novel role as a neurotransmitter in the DG and regulates the strength of GABAergic inputs to the pool of dividing neural progenitors. Hence, SDF-1/ CXCR4 signaling is likely to be an important regulator of adult neurogenesis in the DG.
\end{abstract}

Key words: cytokine; dentate gyrus; GABA; hippocampus; neurogenesis; transgenic; SDF-1/CXCL12; CXCR4

\section{Introduction}

Neural stem cells residing in the subgranular zone (SGZ) of the adult hippocampal dentate gyrus (DG) generate new granule neurons throughout life (Kempermann et al., 2004; Zhao et al., 2006). However, little is known about the physiological mechanisms that normally regulate this process. The initial development of DG neural stem cells is thought to occur in a specialized neurovascular niche in which the cells are exposed to both blood born and neuronally released regulatory influences (Palmer et al., 2000). Indeed, numerous substances have been shown to alter the rate or extent of DG neurogenesis (Sohur et al., 2006). One important question is how the granule cell layer, and neuronal activity in general, instructs the pool of developing neural progenitors to increase or decrease the extent of neurogenesis, a process known as "excitation-neurogenesis coupling" (Deisseroth and Malenka, 2005). To this end, it has been demonstrated that neural progenitors initially receive GABAergic inputs and that acti-

\footnotetext{
Received Feb. 4, 2008; revised May 13, 2008; accepted May 15, 2008.

This work was supported by grants from the National Institutes of Health and the Dana Foundation.

Correspondence should be addressed to Richard J. Miller, Department of Molecular Pharmacology and Biological

Chemistry, Feinberg School of Medicine, Northwestern University, Chicago, IL 60611. E-mail:

r-miller10@northwestern.edu.

DOI:10.1523/JNEUROSCI.1677-08.2008

Copyright $\odot 2008$ Society for Neuroscience $\quad 0270-6474 / 08 / 286720-11 \$ 15.00 / 0$
}

vation of $\mathrm{GABA}_{\mathrm{A}}$ receptors expressed by neural progenitors can influence their proliferation and subsequent development (Tozuka et al., 2005; Ge et al., 2006). The source of GABA that influences DG neural progenitor function is not precisely known, although it has been suggested that it may be derived from DG interneurons such as basket or axo-axonic cells (Tozuka et al., 2005). DG neural progenitors are initially subject to tonically released GABA and subsequently develop phasic synaptic GABAergic inputs (Tozuka et al., 2005; Ge et al., 2006). As with many immature neurons, these early GABAergic influences generally serve to depolarize DG neural progenitors (Tozuka et al., 2005; Ge et al., 2006). It is thought that GABA-mediated depolarization results in the influx of $\mathrm{Ca}^{2+}$ which then regulates progenitor cell proliferation and development.

The chemokines are a family of small proteins that have been widely studied because of their key role in orchestrating the migration of leukocytes during inflammatory responses. In addition, signaling by the chemokine stromal cell-derived factor-1 (SDF-1; also known as CXCL12) via its receptor CXC chemokine receptor 4 (CXCR4) has been shown to be of great importance in the development of many tissues including the nervous system (Tran and Miller, 2003). In particular, SDF-1/CXCR4 signaling is of key importance in the initial development of the DG (Bagri et al., 2002; Lu et al., 2002). During development, SDF-1 expressed 
by the meninges provides a chemotactic cue for neural progenitors migrating from the lateral ventricle to the nascent DG. SDF-1 also regulates the proliferation of these cells. Interestingly, CXCR4 and SDF-1 are both extensively expressed in the adult DG (Stumm et al., 2002; Tran et al., 2007), suggesting that they may continue to exert an important influence on neurogenesis. We now demonstrate that SDF-1 is localized to nerve terminals of DG neurons and that tonic release of SDF-1 regulates GABAergic inputs to DG neural progenitors. These results suggest that SDF-1 can act as a neurotransmitter and that SDF-1/CXCR4 signaling may contribute to the regulation of neurogenesis in the DG.

\section{Materials and Methods}

Animals. The transgenic mice used in this study were nestin-enhanced

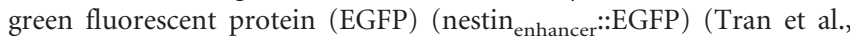
2007) (kindly provided by Anjen Chenn, Northwestern University) and the following bacterial artificial chromosome (BAC) transgenic mice:

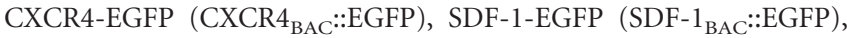

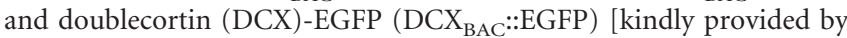
Dr. Mary Beth Hatten (The Rockefeller University, New York, NY) and The Gene Expression Nervous System Atlas (GENSAT) project, National Institute of Neurological Disorders and Stroke contract N01Nso2331 to The Rockefeller University, New York, NY (http://www.gensat.org)]. All animal-related procedures were approved by the Northwestern University animal care and use committee.

Generation of SDF-1-mRFP1 BAC transgenic mice (SDF- $1_{B A C}:: S D F-$ 1-mRFP1). The SDF-1-containing BAC clone (RP23-203H21; the same clone that was used to generate SDF-1-EGFP mice by the GENSAT) was obtained from Invitrogen. To generate SDF-1-BAC reporter vector, monomeric red fluorescence protein 1 (mRFP1) was inserted at the end of the SDF- $1 \alpha$ coding sequence by $\lambda$-Red-mediated recombination with slight modifications (Lee et al., 2001). The mRFP1-FRT-KAN-FRT targeting cassette was generated by self-ligation of blunt-ended BglII-SmaI fragment of pIGCN21 and then replacing the EGFP coding sequence with that of mRFP1 (Lee et al., 2001). The targeting cassette was amplified by PCR using the following chimeric primers, $3^{\prime}$ of which were homologous to targeting cassette and $5^{\prime}$ of which were homologous to the last exon of SDF- $1 \alpha$ : for upstream, 5'-CATTGACCCGAAATTAAAGTGGATCCAAGAGTACCTGGAGAAAGCTTTAAACAAGCCGGTCGCCACCATGGCCTCC-3'; for downstream, 5'-CACTGCCCTTGCATCTCCCACGGATGTCAGCCTTCCTCGGGGGTCTACTGGAAAGCTATTCCAGAAGTAGTGAGGA-3. The primers were designed to target mRFP1 immediately downstream of CCR 2 coding sequence and upstream of poly (A) site. The stop codon of SDF- $1 \alpha$ was deleted to generate SDF-1-mRFP1 fusion construct. In this way, the splicing sites for SDF- $1 \beta$ and SDF- $1 \gamma$ were disrupted, so SDF- $1 \alpha$-mRFP1 would be expressed in any cell where any isoforms of SDF-1 are expressed. Transgenic mice were generated by the Center for Genetic Medicine, Northwestern University.

Histology and immunohistochemistry. Mice (3 to 5 weeks old) were anesthetized and perfused transcardially with cold PBS, followed by a freshly prepared solution of $4 \%$ paraformaldehyde (PFA) in PBS, pH 7.4. The brains were rapidly removed and postfixed overnight in $4 \%$ PFA at $4^{\circ} \mathrm{C}$. Forty-micrometer-thick coronal sections were cut with a vibratome (Leica VT 1000S) and collected in cold PBS. Sections were then processed for histology or immunohistochemistry.

Immunohistochemistry was performed on free-floating sections using the following primary antibodies: Ki67 (1:200; BD Biosceinces PharMingen), bromodeoxyuridine (BrdU; 1:500; Fitzgerald), parvalbumin (1: 500; Swant), BrdU antibody (Fitzgerald), vesicular GABA transporter (VGAT; 1:200; Synaptic Systems), synaptotagmin 1 (1:400; Synaptic Systems), synaptoporin (1:400; Synaptic Systems), synaptic vesicle protein 2 (SV2; 1:400; Synaptic Systems), and bassoon (1:400, Assay Designs). The appropriate isotype-specific secondary antibodies consisted of AlexaFluor 633-conjugated preparations (1:400; Invitrogen).

Sections were incubated in PBS/10\% normal serum of a host where the secondary antibody was raised/0.5\% Triton X-100 for 90 min at room temperature (RT). They were then incubated with primary antibodies diluted in PBS $/ 3 \%$ normal serum $/ 0.1 \%$ Triton X-100, $24 \mathrm{~h}$ at $4^{\circ} \mathrm{C}$. The sections were then washed with PBS and incubated with secondary antibodies diluted in PBS/1\% normal serum for $1 \mathrm{~h}$. Sections were washed with PBS, mounted on slides, and analyzed by a confocal microscopy.

For the staining of blood vessels, tomato lectin (from Lycopersicon esculentum) conjugated to FITC (Vector Laboratories) was allowed to circulate for 5 min before the animals were perfused with 4\% PFA.

$\mathrm{BrdU}$ labeling. Adult mice received intraperitoneal injections of BrdU [Sigma-Aldrich; $50 \mathrm{mg} / \mathrm{kg}$ body weight; dissolved in sterile PBS (10 mg/ $\mathrm{ml}$ ) and filtered at $0.22 \mu \mathrm{m}$ ]. To label dividing cells in the adult brain, mice were given three injections separated by 2 h. Twenty-four hours after the first injection, animals were anesthetized and perfused transcardially with PBS, followed by a freshly prepared solution of $4 \%$ PFA in $\mathrm{PBS}, \mathrm{pH}$ 7.4. The brains were rapidly removed and postfixed overnight in $4 \%$ PFA at $4^{\circ} \mathrm{C}$. Forty-micrometer-thick coronal free-floating sections were cut with a vibratome (Leica VT 1000S) and collected in cold PBS. Brain sections were incubated for $20 \mathrm{~min}$ in $2 \mathrm{~N} \mathrm{HCl}$ at $37^{\circ} \mathrm{C}$ before subjected to immunohistochemistry.

Plasmid construction and adenovirus production. SDF-1-mRFP1 was made by cloning PCR fragment of SDF-1 protein coding sequence into pmRFP1-N1 (a kind gift from Dr. Roger Tsien, University of California, San Diego, La Jolla, CA). Sequence identity was confirmed by dideoxysequencing methods. To make adenoviruses, the fragments containing promoter, protein coding sequence, and poly-A signal were cloned into pShuttle vector and adenovirus was generated using AdEasy system $(\mathrm{He}$ et al. 1998). Chemicals were purchased from Sigma-Aldrich unless stated otherwise.

Cell culture and transfection. F11 [a neuronal cell line derived from dorsal root ganglion (DRG) neurons] (Francel et al., 1987) cells were maintained in DMEM supplemented with $10 \%$ fetal bovine serum (FBS), $0.5 \%$ penicillin-streptomycin $(\mathrm{P} / \mathrm{S})$ at $37^{\circ} \mathrm{C}$ under $5 \% \mathrm{CO}_{2}$. One microgram of plasmid DNA was transfected using Mirus-LT1 according to the manufacturer's instructions. To induce differentiation of F11 cells, the medium was changed to DMEM supplemented with $0.5 \% \mathrm{FBS}, 0.5 \% \mathrm{P} / \mathrm{S}$, and $0.5 \mathrm{~mm}$ dibutyryl-cAMP $24 \mathrm{~h}$ after the transfection. Cells were incubated for $48-72 \mathrm{~h}$ to induce differentiation. Materials for cell culture were purchased from Invitrogen unless stated otherwise.

$D R G$ neuronal culture and adenoviral transduction. Mouse dorsal root DRG neurons were prepared as described previously with slight modifications (Jung et al., 2008). Cells were plated on poly-L-lysine (BD Biosciences)- and laminin (BD Biosciences)-coated coverslips and incubated in F12 supplemented with $0.5 \%$ FBS, $1 \%$ N2, $50 \mathrm{ng} / \mathrm{ml} \mathrm{NGF}$, and $0.5 \% \mathrm{P} / \mathrm{S}$. On the next day, $10 \mu \mathrm{M}$ cytosine arabinoside was added to eliminate mitotic cells including ganglionic fibroblasts. Medium was replaced every $2-3 \mathrm{~d}$. Cultures were maintained at $37^{\circ} \mathrm{C}$ with $5 \% \mathrm{CO}_{2}$ for up to 2 weeks. After 3-5 d in culture, DRG neurons were infected with adenovirus expressing SDF-1-mRFP1 with 50-100 multiplicity of infection and used in 3-5 d.

Hippocampal slice preparation. Hippocampal slices were prepared from 3- to 4-week-old nestin-EGFP or DCX-EGFP mice. Animals were deeply anesthetized and then decapitated. The brains were removed quickly and placed into ice-cold cutting solution of the following composition (in mM): 234 sucrose, $28 \mathrm{NaHCO}_{3}, 2.5 \mathrm{KCl}, 1.25 \mathrm{NaH}_{2} \mathrm{PO}_{4}, 0.5$ $\mathrm{CaCl}_{2}, 7 \mathrm{MgCl}_{2}, 7$ glucose, 1 ascorbic acid, and 3 pyruvic acid, saturated with $95 \% \mathrm{O}_{2} / 5 \% \mathrm{CO}_{2}$ at $\mathrm{pH}$ 7.4. For each experiment, coronal sections of dentate gyrus $(300 \mu \mathrm{m})$ were obtained with a vibratome and kept for 30 min at $37^{\circ} \mathrm{C}$ in oxygenated standard artificial CSF (ACSF) (in mM): 130 $\mathrm{NaCl}, 24 \mathrm{NaHCO}_{3}, 3.5 \mathrm{KCl}, 1.25 \mathrm{NaH}_{2} \mathrm{PO}_{4}, 1.5 \mathrm{CaCl}_{2}, 1 \mathrm{MgSO}_{4}$, and 10 glucose, saturated with $95 \% \mathrm{O}_{2} / 5 \% \mathrm{CO}_{2}$ at $\mathrm{pH}$ 7.4. Slices were stored in modified interface chamber for $30-40 \mathrm{~min}$ at $37^{\circ} \mathrm{C}$ and then maintained at room temperature until being transferred to the recording chamber in oxygenated standard ACSF containing (in $\mathrm{mm}$ ) $130 \mathrm{NaCl}, 24 \mathrm{NaHCO}_{3}$, $3.5 \mathrm{KCl}, 1.25 \mathrm{NaH}_{2} \mathrm{PO}_{4}, 1.5 \mathrm{CaCl}_{2}, 1 \mathrm{MgSO}_{4}$, and 10 glucose, saturated with $95 \% \mathrm{O}_{2}$ and $5 \% \mathrm{CO}_{2}$ at $\mathrm{pH}$ 7.4. The GFP-positive cells were observed with the aid of a fluorescence microscope (BX-50WI; Olympus) and visualized with a chilled charge-coupled device video camera (DageMTI) with a $40 \times$ water-immersion differential interference contrast objective. After identification of the GFP signals, the light path of the mi- 
croscope was switched to the infrared differential interference contrast (infrared DIC) optics mode. Infrared DIC images were monitored on a video monitor, which helped for visual guidance of the patch electrode, for morphological analyses and identification of the location of the recorded neuron. All experiments performed here were performed in accordance with animal experimentation protocols approved by the $\mathrm{Na}$ tional Institutes of Health and institutional protocols.

Electrophysiological recordings. Whole-cell patch-clamp recordings were performed from $\mathrm{GFP}^{+}$cells located in the subgranular zone (hilar region) and $\sim 10-20 \mu \mathrm{m}$ below the surface of the slice of hippocampus as described. Type 2 cells were identified by their GFP-labeled cell body, shape with poorly developed processes, and high input resistance (IR) value $(>0.5 \mathrm{G} \Omega)$. Differential interference contrast and fluorescent images were combined for simultaneous viewing of GFP-labeled and -unlabeled cells.

For whole-cell recordings, patch electrodes with a resistance of 5-7 $\mathrm{M} \Omega$ were pulled from borosilicate capillaries (World Precision Instruments; PG52165-glass) using a P-97 pipette puller (Sutter Instrument). Patch pipettes were filled with a solution that mimicked the intracellular environment and that contained (in $\mathrm{mm}$ ) $150 \mathrm{KCl}, 10 \mathrm{HEPES}, 4 \mathrm{Mg}_{2} \mathrm{ATP}$, $0.5 \mathrm{NaGTP}$, and 10 phosphocreatine. The $\mathrm{pH}$ was adjusted to 7.3 with $\mathrm{KOH}$. The IR and resting membrane potential were measured from each cell. No compensation was made for liquid junction potentials. Wholecell voltage-clamped recordings were obtained from the fluorescencelabeled cells using an Axopatch 200B patch-clamp amplifier (Molecular Devices) and the data were captured with pClamp 9.0 software (Molecular Devices). Series resistance (8-25 M $\Omega$ ) was monitored, and experiments were discarded if substantial changes were observed. SDF- $1 \alpha$ (BD Biosciences), AMD3100, bicuculline methiodide, 6-cyano-7nitroquinoxaline-2,3-dione (CNQX), dl-2-amino-phosphonovaleric acid (APV), tetrodotoxin (TTX), and $\mathrm{CdCl}_{2}$ were applied by either focal or bath application. Cells were clamped at $-70 \mathrm{mV}$ and recording was obtained in presence of $10 \mu \mathrm{M}$ CNQX and $50 \mu \mathrm{M}$ APV. After the recording session, the patch electrode was carefully removed from the cell, and the pipette tip fluorescence was checked to make sure GFP-positive cells are patched.

Data analysis. Data were filtered at $2 \mathrm{kHz}$ and digitized at $10 \mathrm{kHz}$ using a Digidata 1322A analog-to-digital board. Analysis was performed using the pClamp 9.0 (Molecular Devices), MiniAnalysis (Synaptosoft), Sigmaplot (Systat), Igor Pro 5.02 (Wavemetrics), and Prism (GraphPad) software packages. For tonic current measurement, Igor Pro 5.02 was used to load the digitized recording and in this method, the baseline was calculated by generating all-point histograms of $10 \mathrm{~s}$ epochs at control and drug-treated conditions (Nusser and Mody, 2002). A Gaussian distribution was fitted to the positive side of the all-point histograms and the differences between the means of the fitted Gaussians were then calculated.

For the detection and measurement of PSCs: all PSCs were detected in 1 to 3 min recording segments under the appropriate experimental configuration (baseline control, drug application). Event frequency and amplitude were determined by MiniAnalysis software (Synaptosoft).

SDF-1 release and ELISA. Hippocampi were dissected from postnatal day 14 mice and digested with papain at $37^{\circ} \mathrm{C}$ for $20 \mathrm{~min}$. After trituration, granule cell fraction was purified by Percoll gradient centrifugation (60\% Percoll, 30\% Percoll, and cell suspension from bottom to top layers; centrifugation at $8000 \times g$ for $15 \mathrm{~min}$; granule cell fraction isolated from the middle layer). Granule cell-enriched fraction was plated on poly-D-lysine treated 12-well plates in Neurobasal medium (Invitrogen) containing $2 \mathrm{~mm}$ L-glutamine, $1 \times \mathrm{B}-27$, and $1 \times \mathrm{N} 2$ supplements. After $2 \mathrm{~d}$ in culture, a sandwich ELISA for SDF-1 was performed. Cells were washed with a balanced salt solution (BSS) containing (in mM) $140 \mathrm{NaCl}$, $5 \mathrm{KCl}, 2 \mathrm{CaCl} 2,1 \mathrm{MgCl} 2$, and 10 glucose, $\mathrm{pH}$ 7.4. And then cells were incubated with normal BSS or with high-potassium BSS containing (in mм) $95 \mathrm{NaCl}, 50 \mathrm{KCl}, 2 \mathrm{CaCl} 2,1 \mathrm{MgCl} 2,10$ and glucose, $\mathrm{pH}$ 7.4, for $1 \mathrm{~h}$. Supernatant was centrifuged again at $3000 \times g$ for 5 min to exclude possible contamination of floating cells. SDF-1 in the supernatant was measured by a standard sandwich ELISA. Briefly, a 96-well plate was coated with a capture antibody (goat polyclonal anti-SDF-1 antibody, 1:200, C-19; Santa Cruz Biotechnology) in carbonate-bicarbonate buffer,
$\mathrm{pH} 9.7$, at $4^{\circ} \mathrm{C}$ overnight. After blocking with $10 \%$ normal donkey serum in PBS containing 0.05\% Tween-20 (PBS-T) for $2 \mathrm{~h}$ at RT, samples were added to the wells and the plate was incubated for $6 \mathrm{~h}$ at RT. After washing (five times with PBS-T), a detection antibody (mouse monoclonal anti-SDF-1 antibody, 1:1000, P-159X; Santa Cruz Biotechnology) diluted in the blocking solution was added and the plate was incubated at $4^{\circ} \mathrm{C}$ overnight. After washing, a secondary antibody (donkey antimouse-IgG-HRP; 1:10,000; Santa Cruz Biotechnology) was added. After $2 \mathrm{~h}$, the plate was washed and TMB-One (Promega) was added. After 10 min, the reaction was stopped by $1 \mathrm{~N} \mathrm{HCl}$ and OD450 was measured. A standard curve was obtained by total cell lysate diluted serially in BSS, and release was expressed as a percentage of cell contents.

Statistical analysis. Values are given as mean \pm SEM. Statistical comparisons were performed by unpaired Student's $t$ test (supplemental Fig. $2 d$, available at www.jneurosci.org as supplemental material) or by oneway ANOVA followed by Bonferroni's post hoc multiple-comparison test (the rest of the figures). $p<0.05$ was considered statistically significant. The Kolmogorov-Smirnov two-sample, two-tailed test was used to compare the amplitude distribution of the phasic currents.

\section{Results}

To investigate the functions of SDF-1/CXCR4 signaling in the DG of young mice, we made use of different types of EGFP BAC reporter mice. The characteristics of these mice have been described previously (http://www.gensat.org) (Tran et al., 2007). In particular, it has been demonstrated that the expression of EGFP in the brains of the SDF-1 and CXCR4 reporter mice closely resembles that observed using in situ hybridization, and that several lines of the transgenic mice generated by the same BAC clones showed consistent expression patterns (http://www. gensat.org). Therefore, EGFP expression faithfully represents the cellular localization of SDF-1 and CXCR4 expression in these mice.

It has been demonstrated previously that SDF-1/CXCR4 signaling is essential for the migration and proliferation of the neural stem cells that form the DG during its initial development (Bagri et al., 2002; Lu et al., 2002). However, both CXCR4 and its ligand, the chemokine SDF-1, are extensively expressed in the DG of adult mice, particularly in the SGZ (Tran et al., 2007) (Fig. $1 a, b)$. To understand the functions of CXCR4 signaling in the DG of young mice, we wished to determine the precise cellular localization of these molecules. Previous studies have suggested that CXCR4 is expressed by neural stem cells in the DG as well as their progeny, which include the early stages of granule cell development (Tran et al., 2007). To further test this hypothesis, we isolated nestin-EGFP- (Fig. 1c) and DCX-EGFP-expressing (Fig. 1d) cells from reporter mice by fluorescence-activated cell sorting (FACS) and found that they expressed high levels of CXCR4 receptor mRNA (Fig. 1e,f). Cells isolated in this manner also stained with an antibody against CXCR4 receptors (data not shown). Because nestin and DCX are expressed by neural progenitors and migrating neuroblasts, respectively (Kempermann et al., 2004), this indicates that CXCR4 is expressed by DG neural progenitors during the early stages of their development. We also labeled dividing cells in the DG by administering BrdU to CXCR4-EGFP BAC reporter mice and localized BrdU using immunohistochemistry. We observed that CXCR4-EGFP cells in the SGZ frequently incorporated BrdU, further indicating that they were actively proliferating (Fig. $1 g$ ). These data demonstrate that CXCR4-expressing cells in the SGZ include a population of dividing neural progenitors, suggesting that CXCR4 signaling may continue to play a role in their development.

The ligand for CXCR4 receptors is the chemokine SDF-1. During development of the DG, SDF-1 is highly expressed in the meninges (Lu et al., 2002). However, examination of the distri- 

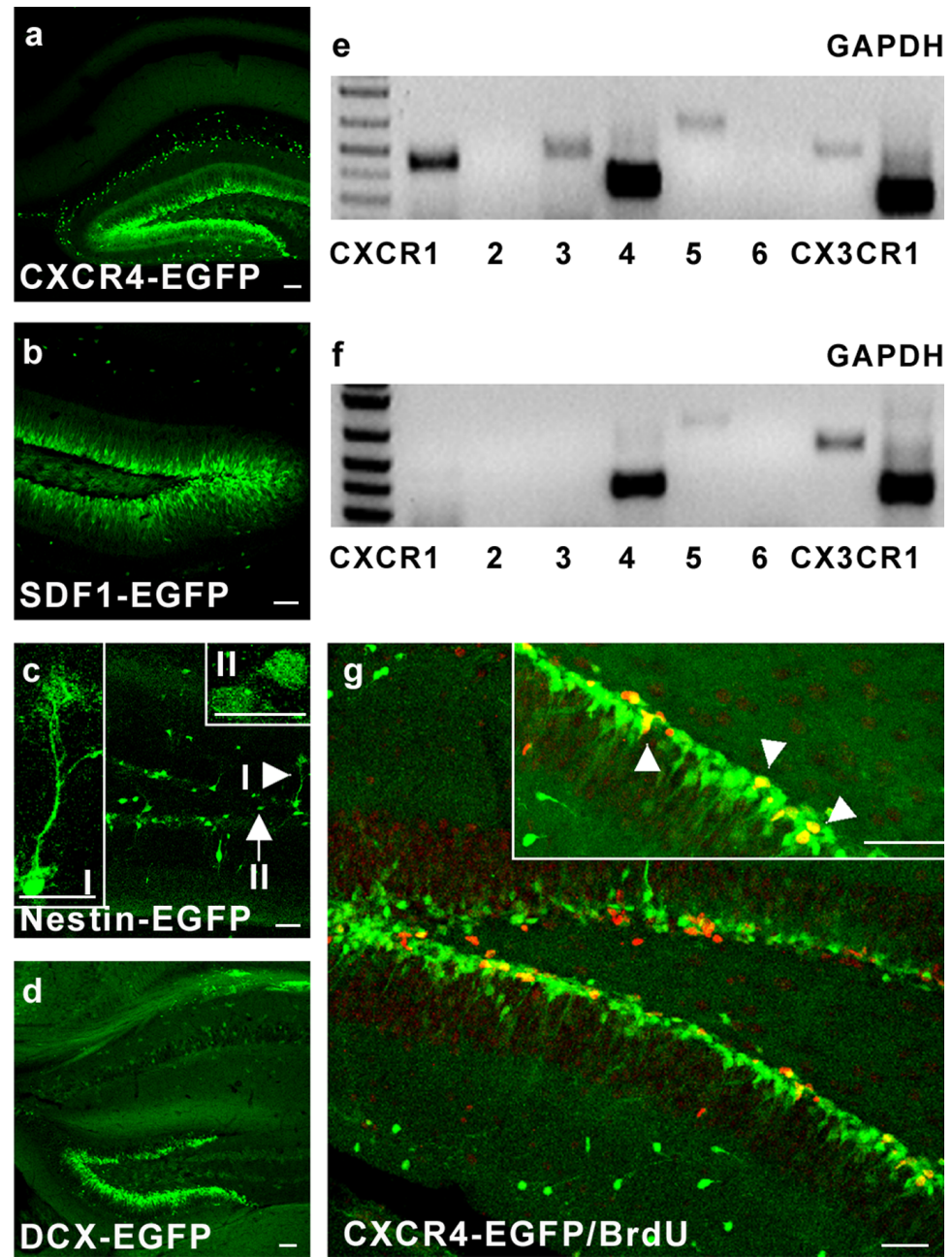

Figure 1. Expression of SDF- 1 and CXCR4 in the adult mouse dentate gyrus. $\boldsymbol{a}-\boldsymbol{d}$, CXCR4, SDF-1, nestin, and DCX are al expressed in the dentate gyrus of EGFP BAC reporter mice (4 weeks). In c, the arrowhead illustrates an example of a nestin-EGFPexpressing type 1 cell. Arrow illustrates an example of a nestin-EGFP-expressing type 2 cell. $\boldsymbol{e}, \boldsymbol{f}, \mathrm{RT}$-PCR analysis of CXC chemokine receptor expression by FACS derived cells isolated from the DG of nestin-EGFP $(\boldsymbol{e})$ and DCX-EGFP $(\boldsymbol{f})$ transgenic BAC reporter mice. Note the robust CXCR4 expression in both populations of cells. $\boldsymbol{g}$, Colocalization of BrdU labeling (red, immunohistochemistry) with CXCR4-EGFP-expressing cells (arrowheads) in the DG of CXCR4-EGFP BAC reporter mice (4 weeks). Scale bars: $\boldsymbol{a}-\boldsymbol{d}, \boldsymbol{g}, 50 \mu \mathrm{m}$; c, insets I, II, $20 \mu \mathrm{m}$.

bution of SDF-1 in the DG of 4-week-old animals using SDF-1EGFP BAC reporter mice (Fig. $1 b$ ), immunohistochemistry, or in situ hybridization (Stumm et al., 2002; Banisadr et al., 2003; Miller et al., 2005; Tran et al., 2007) suggests that it is subsequently expressed in DG neurons. Chemokines are well known to be important regulators of leukocyte trafficking. However, what is the significance of a chemokine expressed by a neuron? We have observed that expression of fluorescent chemokine reporter fusion proteins, including monocyte chemotactic protein-1 (MCP-1)/CCL2 and SDF-1-mRFP1 or EGFP, in cultured neurons results in their processing by the Golgi apparatus and subsequent packaging into synaptic vesicles localized in neurites (Jung et al., 2008) (supplemental Fig. 1a,b, available at www. jneurosci.org as supplemental material). These vesicles can be released from DRG neurons in a depolarization and $\mathrm{Ca}$ dependent manner (Jung et al., 2008) (H. Jung and R. J. Miller, unpublished observations). Both endogenous chemokines and chemokines tagged with fluorescent proteins are targeted to vesicles and released by depolarization. In contrast, when EGFP or mRFP1 are expressed in these same neurons, they show a pattern in which they are not localized to vesicles and fill the entire cell (supplemental Fig. 1c, available at www.jneurosci. org as supplemental material). These proteins are also not released by depolarization. Such observations suggest that the normal distribution and release of chemokines is not altered by modification with fluorescent protein tags (Jung et al., 2008), something that is also true with other small proteins such as growth factors when they are tagged and expressed in neurons (Egan et al., 2003; Shakiryanova et al., 2006). Because of its neuronal localization in the DG of young mice, we hypothesized that SDF-1 might act as a neurotransmitter.

To examine the precise subcellular localization of SDF-1 in the DG, we made a $\mathrm{BAC}$ transgenic mouse line in which mRFP1 was fused to the $\mathrm{C}$ terminus SDF-1. In these mice, mRFP1 was inserted immediately upstream of the SDF- $1 \alpha$ termination codon using the same BAC clone used to generate the SDF-1-EGFP reporter mice discussed above, whose specificity was confirmed by the similar expression patterns observed in different lines of transgenic mice made from this BAC clone (http://www.

gensat.org). Cells in which endogenous signaling drives the expression of SDF-1 will make the SDF-1-mRFP1 fusion protein in addition to the normal endogenous isoform of SDF-1. Because there are no known cleavage sites in the $\mathrm{C}$ terminus, SDF-1-mRFP1 is expected to be a good marker for intracellular localization of endogenous SDF-1. Using these mice, we observed that SDF-1-mRFP1 was expressed in cell types where it would normally be expected, based on previous studies (supplemental Fig. $1 d-j$, available at www.jneurosci.org as supplemental material). This includes endothelial cells associated with blood vessels, the bone marrow, and different types of neurons, such as those in the hippocampus and cerebellum (Stumm et al., 2002; Banisadr et al., 2003; Miller et al., 2005; Sugiyama et al., 2006) (Fig. $2 a$; supplemental Fig. $1 d-j$, available at www.jneurosci.org as supplemental material). Although the same BAC clone was used to make the EGFP reporter mouse and the SDF-1-mRFP1 mouse, and the general cellular expression pattern of the two fluorescent molecules was very similar, the subcellular distribution of EGFP and mRFP1 was quite different. In the SDF-1-EGFP reporter mouse, freely diffusible EGFP filled the entire cell including the cell body and neurites (Fig. 1b). However, as we predicted, expression of SDF-1-mRFP1 in neurons was restricted to vesicle like structures, many of which were localized in cell processes. In the hippocampus, punctate structures expressing SDF-1-mRFP1 were observed to be widely distributed in areas including the hilus, molecular layer and SGZ of the DG (Fig. 2a). Appropriately, this is an identical distribution pattern to that observed using immunohistochemistry to detect endogenous SDF-1 (Miller et al., 2005) Three types of signals 

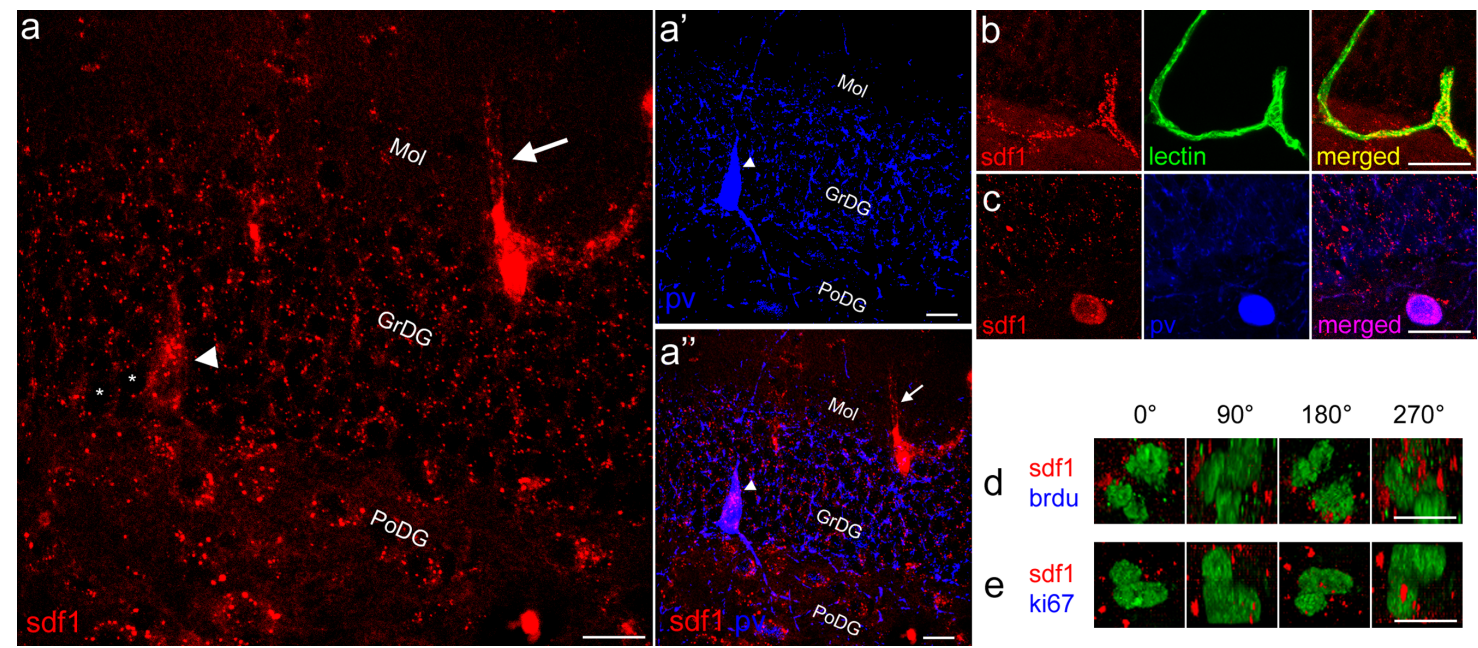

Figure 2. SDF-1 is expressed in synaptic vesicles in the adult mouse dentate gyrus. $\boldsymbol{a}$, SDF-1-mRFP1 expression in numerous vesicles like structures throughout the dentate gyrus from an SDF-1-mRFP1 BAC transgenic mouse (4 weeks). The arrows show a blood vessel. The arrowheads illustrate SDF-1-mRFP1-containing vesicles within the cell body of a basket cell. The asterisks illustrate unlabeled cell bodies surrounded by SDF-1-mRFP1-containing synaptic vesicles. GrDG, Granule cell layer of DG; PoDG, polymorphic layer of the DG. $\boldsymbol{a}^{\prime}$, The same section stained with parvalbumin (pv). $\boldsymbol{a}^{\prime \prime}$, Merged image. $\boldsymbol{b}$, Confocal microscopy reveals expression of SDF-1-mRFP1 in association with blood vessels (tomato lectin, green) in the DG. $\boldsymbol{c}$, Confocal microscopy reveals that SDF-1-mRFP1 is localized to vesicles within a pv-expressing neuron (basket cell) in the DG. $\boldsymbol{d}, \boldsymbol{e}$, SDF-1-mRFP1-labeled nerve terminals (red puncta) are localized in close proximity to dividing cells in the DG labeled by BrdU incorporation (d) and Ki67 staining (e) (both green). Scale bars: $\boldsymbol{a}-\boldsymbol{a}^{\prime \prime}, 20 \mu \mathrm{m} ; \boldsymbol{b}, \boldsymbol{c}, 32 \mu \mathrm{m} ; \boldsymbol{d}, \boldsymbol{e}, 10 \mu \mathrm{m}$.

were readily distinguishable (Fig. 2a). First SDF-1-mRFP1expressing vesicles were aligned with small tube-like structures which proved to be blood vessels, as they could be labeled by perfusion with tomato lectin (Fig. $2 a, b$ ). Second, SDF-1-mRFP1expressing vesicles were observed within the cell bodies of some neurons (Fig. $2 a, c$ ), and third, terminal like structures containing SDF-1-mRFP1-expressing vesicles were localized around numerous cell bodies (Fig. $2 a$ ). We noted that some of the neurons that contained SDF-1-mRFP1-expressing vesicles had the general morphology of basket cells, a major type of DG interneuron (Blasco-Ibáñez et al., 2000). Indeed, these particular SDF-1mRFP1-expressing cells also expressed parvalbumin, a marker for some types of DG basket cells (Fig. $2 a, c$ ). To precisely determine the relative juxtaposition of sites of CXCR4 and SDF-1 expression, we generated reporter mice which expressed both SDF-1-mRFP1 (red) and CXCR4-EGFP (green) (supplemental Fig. $1 d-j$, available at www.jneurosci.org as supplemental material). We observed that SDF-1-mRFP1-labeled vesicles in parvalbumin positive neurons were often localized in the vicinity of CXCR4-expressing cells in the SGZ, which had the morphology of neural progenitors (Fig. $3 a-c$, supplemental Fig. $2 a-c$, available at www.jneurosci.org as supplemental material). Furthermore, SDF-1-mRFP1-labeled vesicles were also localized in close proximity to dividing cells labeled with BrdU or Ki67 in the SGZ (Fig. $2 d, e$ ). We also prepared SDF-1-mRFP1 (red)/nestin-EGFP (green) and SDF-1-mRFP1 (red)/DCX-EGFP (green) mice, and observed that SDF-1-expressing vesicles were associated with most nestin-expressing cells and many DCX-expressing cells (Fig. $3 d-f$, supplemental Fig. $2 a-c$, available at www.jneurosci.org as supplemental material). SDF-1-mRFP1-labeled vesicles were observed in close juxtaposition to nestin-EGFP-expressing "type 2" cells and DCX-EGFP-expressing cells with an immature morphology exhibiting a round shape and few processes (Fig. $3 d-f$, supplemental Fig. $2 b, c$, available at www.jneurosci.org as supplemental material). Because SDF-1-mRFP1 was expressed in presumed GABAergic basket cells we also examined the relative expression pattern of SDF-1 and VGAT, the high-affinity amino acid transporter expressed by GABA-containing synaptic vesi- cles. Interestingly, SDF-1- and VGAT-labeled vesicles were often localized to the same basket cell nerve terminals in the SGZ. SDF-1/GABA-labeled terminals were frequently observed in close juxtaposition to CXCR4-expressing cells with neural progenitor morphology or with nestin-EGFP or DCX-EGFPexpressing cells (Fig. 3, supplemental Fig. $2 a-c$, available at www.jneurosci.org as supplemental material). Interestingly, however, the basket cells themselves did not express CXCR4 receptors (supplemental Fig. $2 a$, available at www.jneurosci.org as supplemental material). Moreover, SDF-1-mRFP1 expressed in endothelial cells in blood vessels was not colocalized with GABA (Fig. 3). Overall, these data suggest that some of the SDF-1 in the DG is localized to GABA-containing synaptic terminals in parvalbumin-expressing basket cells and that these terminals are localized in close proximity to proliferating CXCR4-expressing neural progenitors in the SGZ. It should also be pointed out that, as discussed above, SDF-1-mRFP1 is localized to numerous punctate structures throughout the hippocampus and the majority of these are presumably not associated with basket cells.

The identity of the SDF-1-mRFP1-containing vesicles was further determined by costaining sections from the DG of SDF1-mRFP1/CXCR4-EGFP mice with antibodies for different markers for synaptic vesicles and nerve terminals. We observed that SDF-1-mRFP1-containing vesicles situated in close proximity to CXCR4-EGFP-expressing cells in the SGZ frequently stained with antibodies against synaptotagmin-1, synaptoporin, or SV2, which are all known to be associated with transmittercontaining synaptic vesicles (Jinno and Kosaka, 2003; Khanna et al., 2007; Leitzell, 2007) (Fig. 4). SDF-1-mRFP1-containing vesicles also colocalized with the protein bassoon, which is a marker for active zones of transmitter release from nerve terminals (Schoch and Gundelfinger, 2006) (Fig. 4). We also prepared cultures of DG granule cells from SDF-1-mRFP1 transgenic mice. Cells in these cultures displayed many SDF-1-mRFP1-containing vesicles. Depolarization of these cultured neurons with $50 \mathrm{~mm} \mathrm{~K}$ produced a large increase in SDF-1 released into the culture medium (supplemental Fig. $2 d$, available at www.jneurosci.org as supplemental material). Hence, it is clear that SDF-1-mRFP1- 

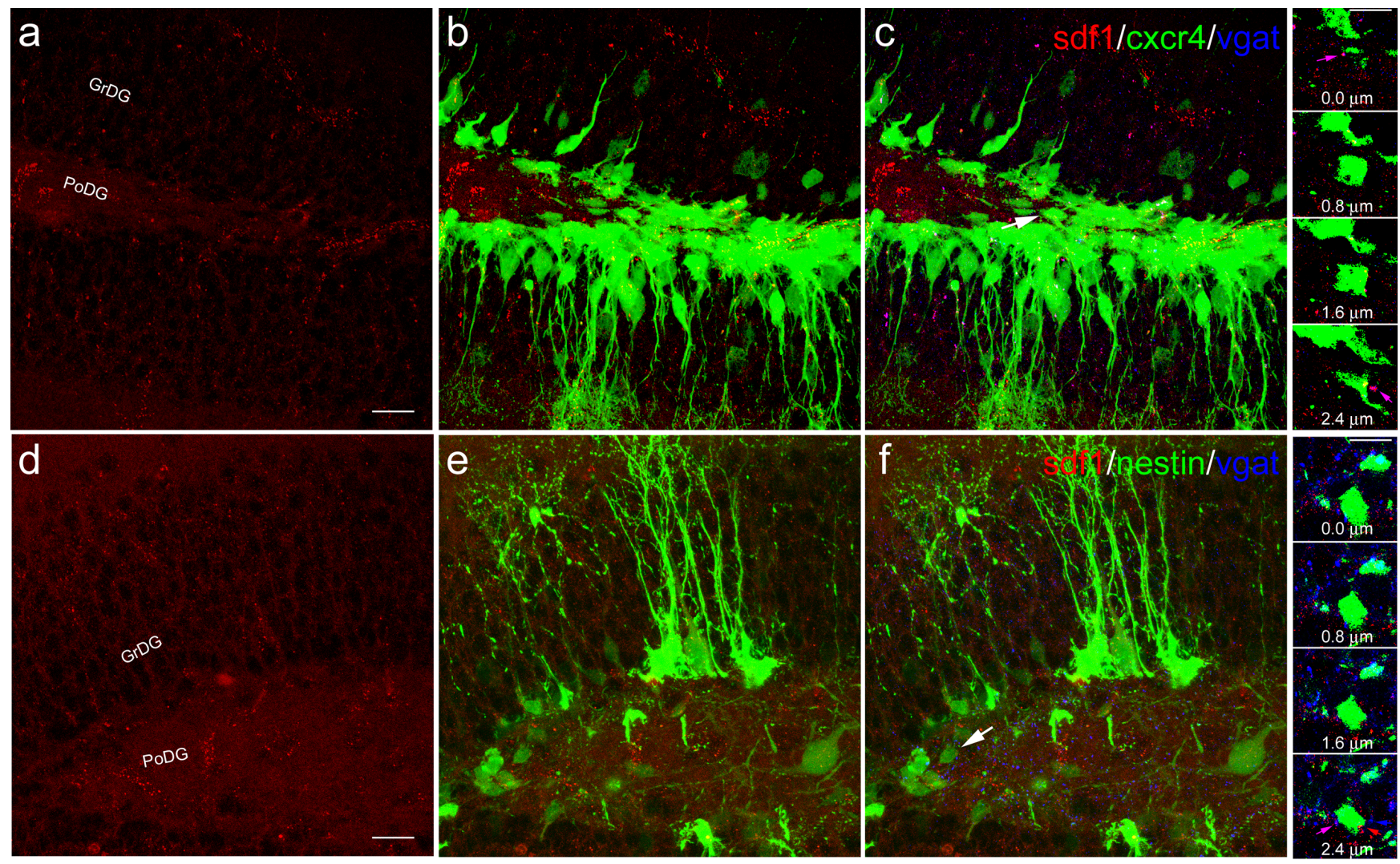

Figure 3. SDF-1-mRFP1 is localized to GABAergic terminals in close proximity to neural progenitors in the DG. $\boldsymbol{a}$-c, SDF-1-mRFP/CXCR4-EGFP bitransgenic mice illustrate the presence of SDF-1-mRFP/VGAT-positive nerve terminal vesicles in close juxtaposition to a CXCR4-EGFP-expressing neural progenitor (arrow). $\boldsymbol{d}$ - $\boldsymbol{f}$, SDF-1-mRFP/nestin-EGFP bitransgenic mice illustrate the presence of SDF-1-mRFP/NGAT-positive nerve terminals close to a nestin-EGFP-expressing type 2 neural progenitor (arrow). $\boldsymbol{c}, \boldsymbol{f}$, Serial optical sections of cells indicated by a white arrow are in the right panels. Red arrows, Terminals just labeled for SDF-1; blue arrows, VGAT only; pink arrows, both SDF-1/VGAT. Examples are from 4-week-old mice. Scale bars: (in $\boldsymbol{a}, \boldsymbol{d}) \boldsymbol{a}-\boldsymbol{f}, 20 \mu \mathrm{m}$; $\boldsymbol{c}$ and $\boldsymbol{f}$ right panels, $8 \mu \mathrm{m}$.

containing vesicles in the DG include a population of nerve terminal associated synaptic vesicles and that these can be released by depolarization, a characteristic feature of such vesicles.

Previous studies have demonstrated that neural stem cells in the adult DG express both nestin and GFAP and have the characteristics of radial glia (Kempermann et al., 2004; Zhao et al., 2006). Rapidly dividing neural progenitors ("transiently amplifying cells") are derived from these stem cells by a process of asymmetric division (Seri et al., 2004). Neural progenitors then develop into granule cells by traversing a well described series of developmental steps (Kempermann et al., 2004; Zhao et al., 2006). Both radial glia like cells (sometimes called type 1 cells) and their immediate progeny (sometimes called type 2 cells or rapidly amplifying cells) are labeled in nestin-EGFP reporter mice (Tozuka et al., 2005). The observations discussed above suggested that, as in the development of the DG, SDF-1 might play a role in the development of granule cells in the mature DG. We therefore examined the effects of SDF-1 on neural progenitor cell function by directly recording from these cells. Type 1 and type 2 cells can be readily distinguished based on their different morphologies (Fig. 1c) and electrophysiological properties. As reported by others, type 1 cells exhibited the electrical properties of glia having a low membrane resistance (Filippov et al., 2003; Tozuka et al., 2005). These cells were also generally unresponsive to the addition of GABAergic or glutamatergic receptor agonists (data not shown). However the properties of type 2 cells were very different (Figs. 5, 6). These cells had high resistance and many cells responded to agonists for $\mathrm{GABA}_{\mathrm{A}}$ or $\mathrm{AMPA}$ receptors.
It has been demonstrated that GABAergic inputs to neural stem cells develop before glutamate mediated inputs (Represa and Ben-Ari, 2005; Tozuka et al., 2005; Ge et al., 2006; Bordey, 2007). Interestingly, these GABAergic inputs initially take the form of a tonic GABA mediated current, which is followed developmentally by phasic GABAergic synaptic transmission (PSC) (Bordey, 2007; Ge et al., 2007). In keeping with these data, recordings from type 2 cells revealed that many cells exhibited an outward current in response to addition of the $\mathrm{GABA}_{\mathrm{A}}$ receptor antagonist bicuculline. Other cells exhibited phasic GABAergic currents, and many cells exhibited both types of GABAergic currents (Fig. $5 a$ ). When SDF-1 was applied during recordings from type 2 cells, it regularly produced a long-lasting inward current (Fig. 5b-d). SDF-1 produced no discernable effects on type 1 cells. The SDF1-induced inward current was completely reversed by bicuculline and no SDF-1 induced current could be observed in cells pretreated with bicuculline, suggesting that the effects of SDF-1 were mediated by activation of $\mathrm{GABA}_{\mathrm{A}}$ receptors (Fig. $5 \mathrm{~g}$ ). In addition, SDF-1 increased both the frequency and amplitude of GABAergic PSCs (Fig. 5h,i). We also examined the effects of SDF-1 in the presence of either TTX or Cd (Fig. $5 e, f, i)$, blockers of voltagedependent $\mathrm{Na}$ and $\mathrm{Ca}$ channels, respectively. The effects of SDF-1 on the tonic and phasic aspects of the current were still observed under these conditions. These data suggest that SDF-1 may normally regulate GABAergic inputs to DG neural progenitors. However, is SDF-1 normally released by neurons in the vicinity of neural progenitors? To test this idea, we added the CXCR4 antagonist AMD3100 which, like bicuculline, regularly produced an 
outward current when recording from type 2 cells (Fig. 6a). SDF-1 was ineffective in cells pretreated with AMD3100 (Fig. 6i). Interestingly, the presence of the AMD3100 mediated current virtually completely occluded the effects of subsequently added bicuculline and the effects of bicuculline occluded the effects of subsequently added AMD3100. AMD3100 also reduced the frequency and amplitude of phasic GABAergic PSCs (Fig. $6 g, h$ ). Hence, we conclude that GABA and SDF-1 are both tonically released and produce GABAergic currents in type 2 cells. Because GABA and SDF-1 are both stored in the terminals of GABAergic interneurons, we hypothesize that these molecules are coreleased and cooperate in producing GABAergic transmission. Because basket cells do not express CXCR4 receptors (supplemental Fig. 2a, available at www. jneurosci.org as supplemental material), we further hypothesize that the effects of SDF-1/GABA are mediated postsynaptically, something that is also consistent with the electrophysiological data. As a further test of this idea, we examined the combined effects of SDF-1 and GABA added to type 2 cells in whole-cell voltageclamp recordings. We consistently observed that the effects of GABA were enhanced when it was added in the presence of SDF-1 (supplemental Fig. 3a, available at www.jneurosci.org as supplemental material).

As a comparison to the effects of SDF- 1 on type 2 cells, we also performed similar electrophysiological studies on DCX-EGFPexpressing cells from BAC reporter mice (Fig. 7). The morphology of DCX-EGFP-expressing cells is much more heterogeneous than those of nestin-EGFP-expressing cells (Tran et al., 2007) (Fig. 1d). We attempted to restrict our recordings to cells with an immature morphology (i.e., round cells with minimal processes). Here, again we observed effects of bicuculline, SDF-1, and AMD3100 on both phasic and tonic currents (Fig. 7). However, a completely different picture was obtained when we recorded from mature granule cells that did not express CXCR4-EGFP. Appropriately, SDF-1 did not produce an inward current in these cells, although small bicuculline induced outward currents were observed as previously reported in the literature (Glykys et al., 2008). In addition, AMD3100 did not produce an outward current in these recordings. Moreover, SDF-1 did not enhance the size of GABAergic PSCs recorded in mature granule cells. In contrast, in the majority of these cells, SDF-1 significantly decreased the magnitude of these PSCs (supplemental Fig. $3 b$, available at www.jneurosci.org as supplemental material). SDF-1 was without effect when added in the presence of AMD3100. These results suggest that the interaction between SDF-1 and $\mathrm{GABA}_{\mathrm{A}}$ signaling we have observed is developmentally regulated and only occurs during early stages of granule cell development.

\section{Discussion}

The experiments described in this study suggest that the chemokine SDF-1 acts as a neurotransmitter in the DG. The evidence supporting this supposition is similar to that available for GABA, certainly a well-established neurotransmitter. Thus, both GABA and SDF-1 are localized in synaptic vesicles within DG nerve terminals. Both GABA and SDF-1 produce similar electrophysiological effects on nestin-EGFP and DCX-EGFP-expressing cells in the SGZ. Moreover, it appears that both GABA and SDF-1 are tonically released in the DG. Thus, addition of both $\mathrm{GABA}_{\mathrm{A}}$ and CXCR4 receptor blockers elicited an outward current, suggesting that GABA and SDF-1 normally exert a tonic influence on type 2 progenitor cells. It also appears that the effects of GABA and SDF-1 are linked in some way because the observed effects of SDF-1 are sensitive to both $\mathrm{GABA}_{\mathrm{A}}$ and CXCR4 blockers.

SDF-1 and its receptor CXCR4 have been shown to be widely expressed throughout the developing and adult nervous systems (Stumm et al., 2002; Banisadr et al., 2003; Tran and Miller, 2003; Tran et al., 2007). Studies using null mice have highlighted the important role that CXCR4 signaling plays during the development of the nervous system. CXCR4 signaling has been shown to play two major roles during neuronal development. One is to act as a chemotactic cue for the migration of neural stem/progenitor cells. Indeed, CXCR4 signaling plays a similar role in the development of many tissues (Zou et al., 1998; Bagri et al., 2002; Lu et al., 2002; Li and Pleasure, 2005). A second role for CXCR4 signaling is in the regulation of axonal pathfinding (Kreibich et al., 2004; Lieberam et al., 2005). However, less is known about the role of SDF-1/CXCR4 in the adult nervous system. SDF-1 has frequently been observed to be constitutively expressed by neurons in the mature brain (Banisadr et al., 2003), and it has been shown to produce effects on neuronal excitability and transmitter release (Guyon and Nahon, 2007). Observations of this type have suggested that SDF-1 may normally play a role in the regulation 
a
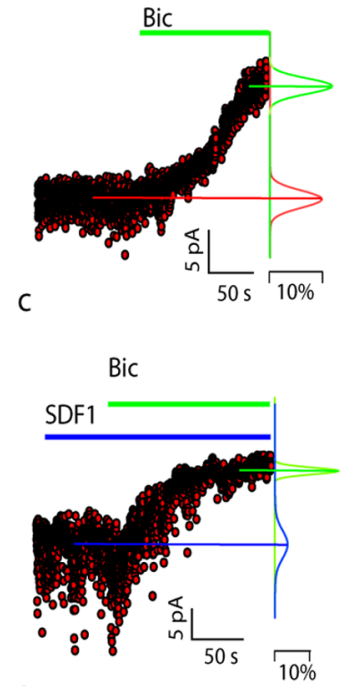

e
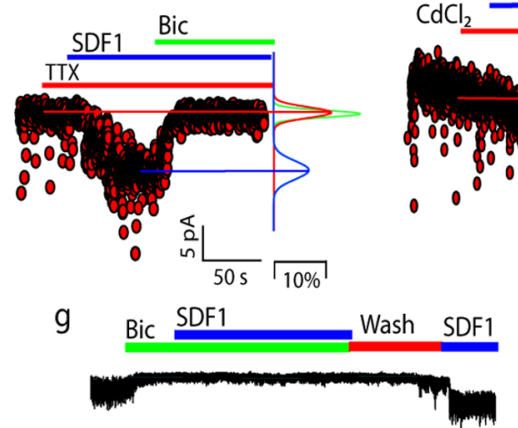

b
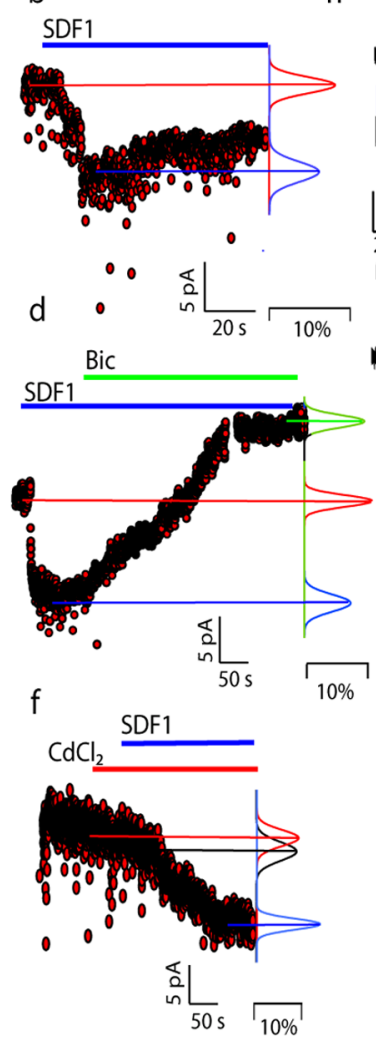

$\mathrm{h}$
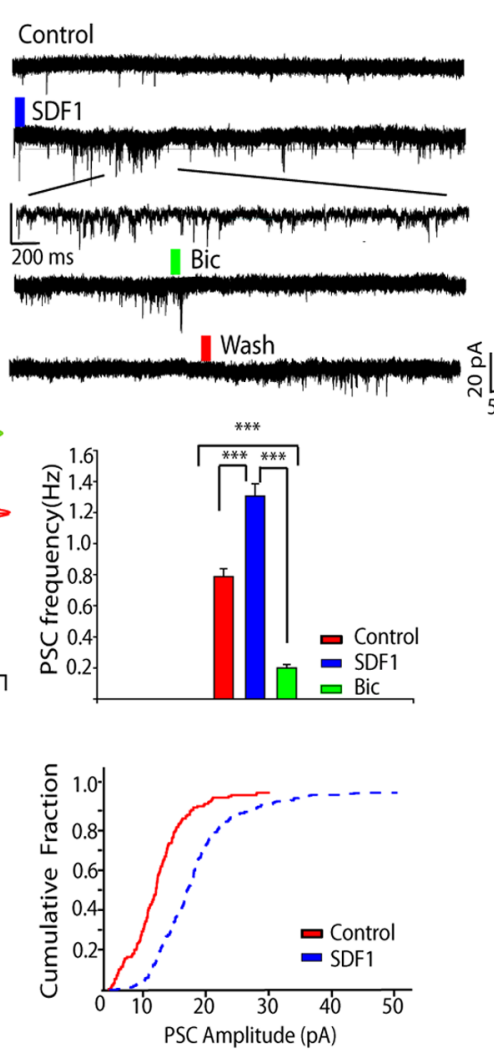

i Control
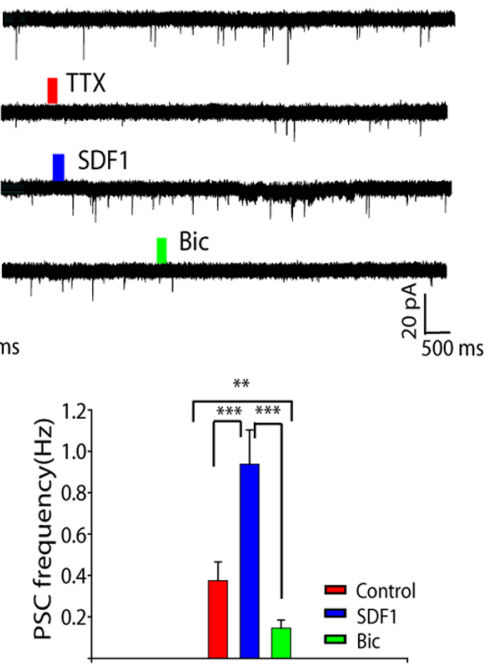

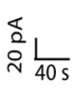

Figure 5. SDF-1 enhances GABA mediated activation of neural progenitors in the dentate gyrus. Recordings taken from type 2 nestin-EGFP-expressing cells in acutely isolated slices from mouse DG are shown. $\boldsymbol{a}$, Bicuculline (Bic; $100 \mu \mathrm{m}$ ) inhibited PSCs and produced an outward current. $\boldsymbol{b}-\boldsymbol{d}$, SDF-1 (40 nm) produced a long-lasting inward current (b), which was reversed by bicuculline (c, $\boldsymbol{d}) . \boldsymbol{e}, \boldsymbol{f}$, The inward current produced by SDF-1 was also observed in the presence of either TTX $(0.5 \mu \mathrm{m}, \boldsymbol{e})$ or $\mathrm{Cd}(10 \mu \mathrm{m}, \boldsymbol{f})$. $\boldsymbol{g}$, SDF-1 was ineffective in cells that were pretreated with bicuculline. $\boldsymbol{h}$, $\boldsymbol{i}$, SDF- 1 increased both the frequency and amplitude of PSCs recorded from type 2 cells ( $\boldsymbol{h}$ ) and this was also the case in the presence of TTX (i). In $\boldsymbol{a}-\boldsymbol{d}, 30$ of 42 cells examined exhibited an outward current in response to bicuculline and 49 of 69 exhibited an inward current in response to SDF-1. In addition, 7 of 12 cells exhibited an inward current in response to SDF- 1 in the presence of TTX and 5 of 9 did so in the presence of $\mathrm{Cd}^{2+}$. SDF-1 increased the frequency and amplitude of 14 of 20 cells examined, and in TTX, 6 of 12 cells. ${ }^{* *} p<0.01$; ${ }^{* * *} p<0.001$. Error bars indicate SEM.

of synaptic communication, although whether SDF-1 is stored in and released from neurons has not been demonstrated. The idea that SDF-1 and other chemokines might act as neurotransmitters is supported by several observations in the literature (de Jong et al., 2005; Fryer et al., 2006; Rostène et al., 2007; Jung et al., 2008). For example, we have observed that, in association with the development of neuropathic pain, expression of the chemokine MCP-1 is upregulated by DRG neurons (Jung et al., 2008). MCP-1 is packaged into the same synaptic vesicles as the neuropeptide CGRP and can be released from these neurons by depolarization in a Ca-dependent manner (Jung et al., 2008). It may therefore be the case that expression of chemokines by neurons is associated with a neurotransmitter role for these molecules. SDF-1 is unusual, however, because it is constitutively expressed in neurons, whereas other chemokines are usually upregulated in response to some pathological event. Hence, it is likely that SDF1/CXCR4 signaling is primarily concerned with the regulation of events in addition to those associated with immunity.

In the experiments reported here, we used a new transgenic mouse model to examine the physiological role of SDF-1 in the DG. We observed that SDF-1-mRFP1 was localized to vesicles in neurons in many parts of the brain (Jung and Miller, unpublished observations) and this distribution pattern was consistent with previous studies on the localization of SDF-1 (Stumm et al., 2002;
Banisadr et al., 2003; Miller et al., 2005). The precise nature of the neuronal vesicles that store SDF-1 is not known. Indeed, despite the fact that some studies have demonstrated the storage of certain chemokines in secretory vesicles in leukocytes (Øynebråten et al., 2004), no studies have investigated the storage pattern for SDF-1 in leukocytes or any other type of cell. In the postnatal DG, we observed that SDF-1-mRFP1was expressed in vesicles by both neurons and endothelial cells associated with blood vessels. SDF1-mRFP1-containing vesicles also expressed a number of proteins known to be associated with neurotransmitter secretory vesicles. Moreover, SDF-1 could be released from granule cells by depolarization. Hence, our conclusion is that SDF-1 is normally stored in a population of synaptic neurotransmitter vesicles in the DG.

Based on the results of experiments examining its cellular and subcellular localization, as well as its electrophysiological effects, SDF-1 appears to act as a neurotransmitter that is released together with GABA from inhibitory interneurons and which cooperates with GABA in communicating with neural progenitor cells. It is not known exactly how SDF-1 potentiates GABAergic transmission. However, our experiments suggest that the observed interaction occurs postsynaptically. Thus, effects of SDF-1 could be observed in the presence of TTX or Cd, and synergistic effects between SDF-1 and GABA were observed in voltage clamp 
a
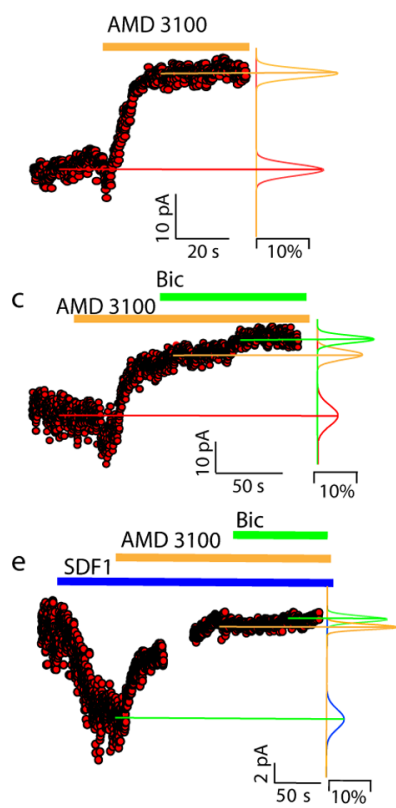

b
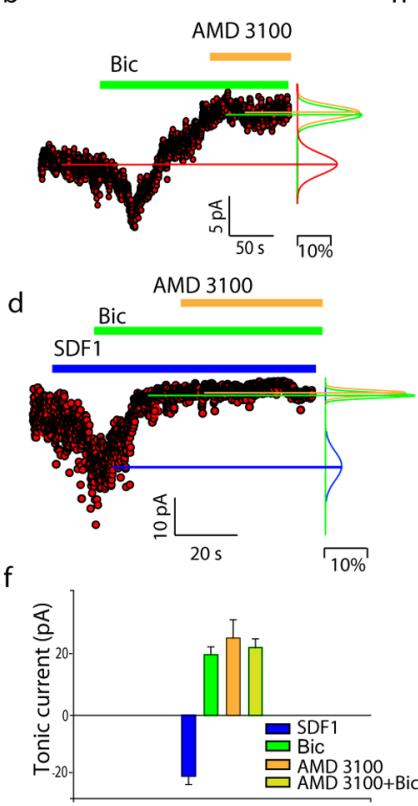

h
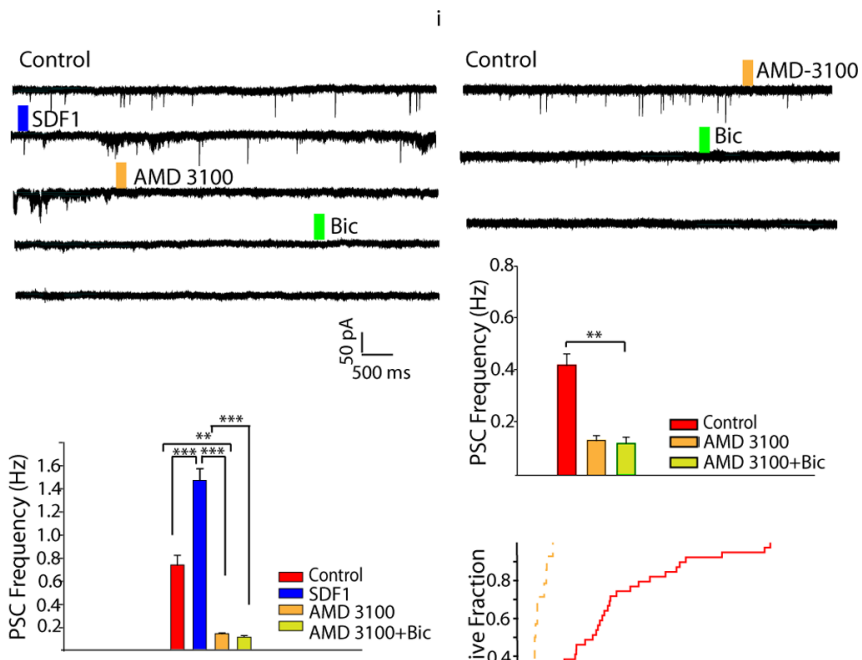

g

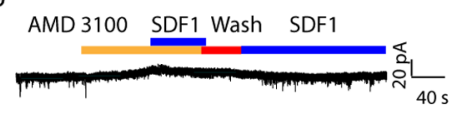

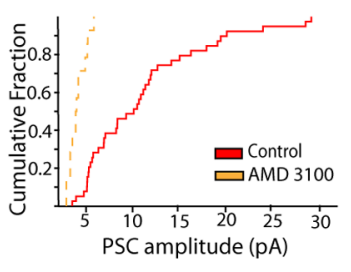

Figure 6. SDF-1 is tonically released in the adult mouse dentate gyrus. Recordings made from nestin-EGFP-expressing type 2 cells in the DG. $\boldsymbol{a}$, The CXCR4 antagonist AMD3100 (1 $\mu \mathrm{m}$ ) produced an outward current. $\boldsymbol{b}-\boldsymbol{f}$, Outward currents produced by AMD3100 or bicuculline $(\boldsymbol{b}, \boldsymbol{c}, 100 \mu \mathrm{m})$ were not additive $(\boldsymbol{d}, \boldsymbol{e}, \boldsymbol{f}, n=44$ cells). $\boldsymbol{g}-\boldsymbol{i}$, SDF-1 increased and AMD3100 reduced the frequency and amplitude of PSCs. These effects of AMD3100 were observed after treatment with SDF-1 $(\boldsymbol{g})$ or in its absence $(\boldsymbol{h}) .{ }^{* *} p<0.01 ;{ }^{* * *} p<0.001$. $\boldsymbol{i}$, SDF-1 was unable to produce an effect in the presence of AMD3100, but did so after washout of the antagonist. Error bars indicate SEM.

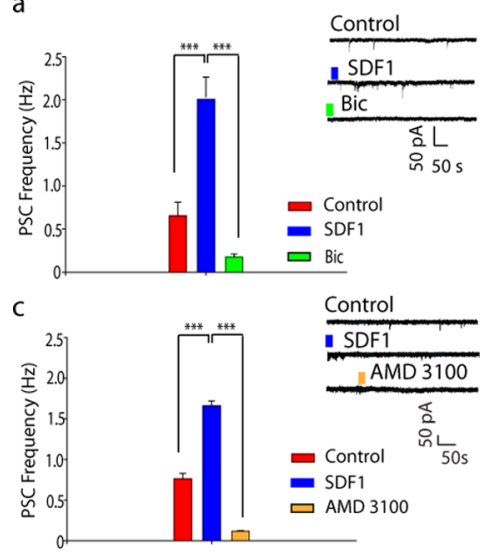

b

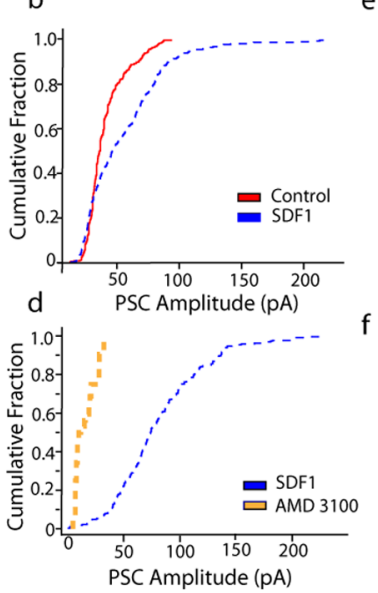

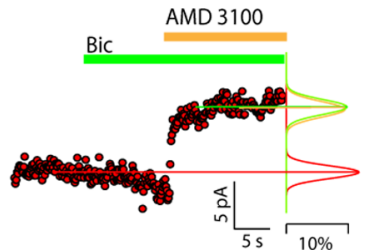

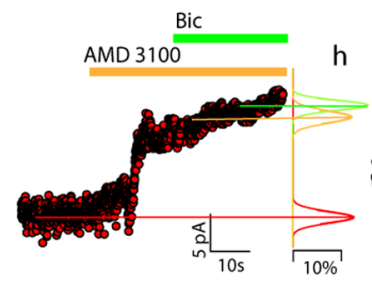

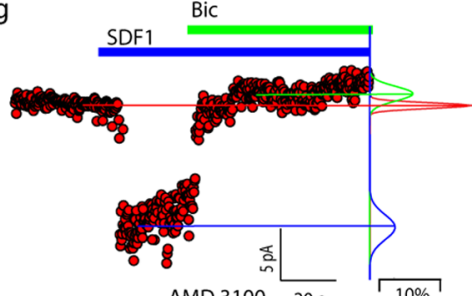

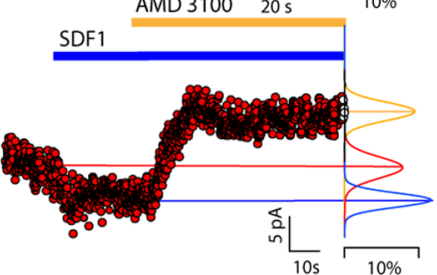

Figure 7. Effects of SDF-1 on GABAergic inputs to DCX-EGFP-expressing cells in the adult mouse dentate gyrus from DCX-EGFP BAC transgenic mice. $\boldsymbol{a}-\boldsymbol{d}$, SDF-1 (40 nm) increased the amplitude and frequency of PSCs recorded in DCX-EGFP-expressing cells with immature morphology and this was reversed by both bicuculline $(\boldsymbol{a}, \boldsymbol{b})$ and AMD3100 $(\boldsymbol{c}, \boldsymbol{d})$. SDF-1 produced this effect in 20 of 56 cells. This was reversed by bicuculline in five of seven cells and by AMD3100 in three of five cells examined. ${ }^{* *} p<0.01 ;{ }^{* * *} p<0.001 . e, f$, Both bicuculline ( 3 of 4 ) and AMD3100 ( 3 of 5 ) produced an outward current in DCX-EGFP cells and their effects were not additive. $\boldsymbol{g}, \boldsymbol{h}$, SDF-1 produced an inward current in DCX-EGFP cells and its effects were reversed by bicuculline ( $\boldsymbol{g}$, 4 of 5 ) and by $\operatorname{AMD} 3100(\boldsymbol{h}, 3$ of 6). Error bars indicate SEM.

studies using EGFP-expressing type 2 progenitor cells. Moreover, CXCR4 is not expressed by basket cells, the likely presynaptic source of SDF-1 and GABA release. Numerous intracellular signaling pathways have been shown to regulate $\mathrm{GABA}_{\mathrm{A}}$ receptors (Song and Messing, 2005; Houston and Smart, 2006). Hence, it is possible that activation of CXCR4 receptors expressed by neural progenitors is able to transactivate $\mathrm{GABA}_{\mathrm{A}}$ receptors expressed by the same cells. It is clear from our data that SDF-1 has an important influence on the effects of GABA because inhibition of CXCR4 receptors often completely occluded any subsequent effects of bicuculline. It is quite possible that the influence of SDF-1 is not constant and that the levels of SDF-1 or of CXCR4 recep- tors may themselves be subject to regulation leading to a contextdependent effect on GABAergic transmission.

It is apparent that the extent of DG neurogenesis in the adult is subject to the influence of numerous factors (Sohur et al., 2006). It is thought that mechanisms must exist by which activity in the granule cell layer can communicate with the pool of developing neural progenitors so that neurogenesis can be regulated in keeping with the precise requirements of the DG (Deisseroth and Malenka, 2005). Indeed, it is clear that changes in neuronal activity in the DG can alter neurogenesis in the context of both normal physiology and pathology (Scharfman and Hen, 2007). Exactly how this feedback mechanism is achieved has not been 
completely understood. However, recent studies have indicated a role for GABAergic transmission and GABAergic inputs to DG neural progenitors have been previously identified (Ge et al., 2006). One possible source are immature granule cells that pass through a GABAergic phase during their development (Gutiérrez, 2003). Another possibility is that the GABA is derived from a type of DG interneuron (Tozuka et al., 2005). Our studies support this possibility, as we observed the terminals of parvalbumin-expressing GABAergic interneurons in close proximity to dividing neural progenitors. Thus, it is likely that neuronal activity in the granule cell layer can regulate the proliferation and differentiation of DG neural progenitors through synaptic connections with basket cells which release GABA and SDF-1 (Deisseroth and Malenka, 2005; Tozuka et al., 2005). As we have now demonstrated, GABAergic transmission to type 2 cells can be regulated by SDF-1, which is also tonically released, raising the possibility that this chemokine plays a role in regulating the same stages of granule cell development. SDF-1 produced similar effects on nestin-EGFP and DCX-EGFP cells. Although this cell population is certainly heterogeneous (Steiner et al. 2006), it does contain the "transiently amplifying population" whose proliferation may be susceptible to external influences. It should be noted that CXCR4 is expressed by SGZ neural progenitor cells from the earliest stages of development (Tran et al., 2007). Thus, CXCR4 is also expressed in type 1 cells that express GFAP and nestin. Cells at this stage do not receive tonic GABAergic inputs (Tozuka et al., 2005; Wang et al., 2005; Ge et al., 2006). Nevertheless, it remains possible that CXCR4 signaling plays another type of role at this point. Furthermore, CXCR4 is also expressed by immature granule cells that express calretinin, although not by mature granule cells that express calbindin (Tran et al., 2007). Hence, it is possible that CXCR4 regulates other steps in granule cell development as well (Pujol et al., 2005).

Neural stem cells in the brain under normal or pathophysiological conditions are thought to reside in niche like structures which are susceptible to both neuronal and blood born influences (Palmer et al., 2000; Ohab et al., 2006). It is therefore interesting to note that, in addition to neurons, SDF-1 in the DG was expressed in endothelial cells associated with blood vessels (Fig. 2, supplemental Fig. 1f,g, available at www.jneurosci.org as supplemental material). Thus, it is possible that SDF-1 released by endothelial cells as well as neurons may coordinate vascular and neuronal influences on DG neural progenitor function. This role may extend to the neurogenic response of the brain to injuries such as stroke (Ohab et al., 2006). Although SDF-1 is expressed by DG basket cells, it is also clearly expressed by other types of neurons throughout the DG and the rest of the hippocampus. It is therefore likely that influencing neural stem cell function as described here is not the only way in which SDF-1 regulates neuronal function throughout the hippocampus, something that is also suggested by other recent publications (Kasiyanov et al., 2007; Parachikova and Cotman, 2007). As our experiments also demonstrate, SDF-1 did not produce currents in mature granule cells which do not appear to express CXCR4 receptors. However, we did observe that the GABAergic input to these cells was reduced by SDF-1, presumably by a presynaptic mechanism. It seems likely, therefore, that SDF-1 produces a number of electrophysiological effects in the DG and that these may be determined by the developmental stage of the neuron involved.

\section{References}

Bagri A, Gurney T, He X, Zou YR, Littman DR, Tessier-Lavigne M, Pleasure SJ (2002) The chemokine SDF1 regulates migration of dentate granule cells. Development 129:4249-4260.
Banisadr G, Skrzydelski D, Kitabgi P, Rostène W, Parsadaniantz SM (2003) Highly regionalized distribution of stromal cell-derived factor-1/CXCL12 in adult rat brain: constitutive expression in cholinergic, dopaminergic and vasopressinergic neurons. Eur J Neurosci 18:1593-1606.

Blasco-Ibáñez JM, Martínez-Guijarro FJ, Freund TF (2000) Recurrent mossy fibers preferentially innervate parvalbumin-immunoreactive interneurons in the granule cell layer of the rat dentate gyrus. Neuroreport 11:3219-3225.

Bordey A (2007) Enigmatic GABAergic networks in adult neurogenic zones. Brain Res Rev 53:124-134.

de Jong EK, Dijkstra IM, Hensens M, Brouwer N, van Amerongen M, Liem RS, Boddeke HW, Biber K (2005) Vesicle-mediated transport and release of CCL21 in endangered neurons: a possible explanation for microglia activation remote from a primary lesion. J Neurosci 25:7548-7557.

Deisseroth K, Malenka RC (2005) GABA excitation in the adult brain: a mechanism for excitation-neurogenesis coupling. Neuron 47:775-777.

Egan MF, Kojima M, Callicott JH, Goldberg TE, Kolachana BS, Bertolino A, Zaitsev E, Gold B, Goldman D, Dean M, Lu B, Weinberger DR (2003) The BDNF val66met polymorphism affects activity-dependent secretion of BDNF and human memory and hippocampal function. Cell 112:257-269.

Filippov V, Kronenberg G, Pivneva T, Reuter K, Steiner B, Wang LP, Yamaguchi M, Kettenmann H, Kempermann G (2003) Subpopulation of nestin-expressing progenitor cells in the adult murine hippocampus shows electrophysiological and morphological characteristics of astrocytes. Mol Cell Neurosci 23:373-382.

Francel PC, Harris K, Smith M, Fishman MC, Dawson G, Miller RJ (1987) Neurochemical characteristics of a novel dorsal root ganglion X neuroblastoma hybrid cell line, F-11. J Neurochem 48:1624-1631.

Fryer AD, Stein LH, Nie Z, Curtis DE, Evans CM, Hodgson ST, Jose PJ, Belmonte KE, Fitch E, Jacoby DB (2006) Neuronal eotaxin and the effects of CCR3 antagonist on airway hyperreactivity and M2 receptor dysfunction. J Clin Invest 116:228-236.

Ge S, Pradhan DA, Ming GL, Song H (2007) GABA sets the tempo for activity-dependent adult neurogenesis. Trends Neurosci 30:1-8.

Ge S, Goh EL, Sailor KA, Kitabatake Y, Ming GL, Song H (2006) GABA regulates synaptic integration of newly generated neurons in the adult brain. Nature 439:589-593.

Glykys J, Mann EO, Mody I (2008) Which GABA A receptor subunits are necessary for tonic inhibition in the hippocampus? J Neurosci 28:1421-1426.

Gutiérrez R (2003) The GABAergic phenotype of the "glutamatergic" granule cells of the dentate gyrus. Prog Neurobiol 71:337-358.

Guyon A, Nahon JL (2007) Multiple actions of the chemokine stromal cellderived factor- $1 \alpha$ on neuronal activity. J Mol Endocrinol 38:365-376.

He TC, Zhou S, da Costa LT, Yu J, Kinzler KW, Vogelstein B (1998) A simplified system for generating recombinant adenoviruses. Proc Natl Acad Sci USA 95:2509-2514.

Houston CM, Smart TG (2006) CaMK-II modulation of GABA(A) receptors expressed in HEK293, NG108-15 and rat cerebellar granule neurons. Eur J Neurosci 24:2504-2514.

Jinno S, Kosaka T (2003) Heterogeneous expression of the cholecystokininlike immunoreactivity in the mouse hippocampus, with special reference to the dorsoventral difference. Neuroscience 122:869-884.

Jung H, Toth PT, White FA, Miller RJ (2008) Monocyte chemoattractant protein-1 functions as a neuromodulator in dorsal root ganglia neurons. J Neurochem 104:254-263.

Kasiyanov A, Fujii N, Tamamura H, Xiong H (2007) Modulation of network-driven, GABA-mediated giant depolarizing potentials by SDF- $1 \alpha$ in the developing hippocampus. Dev Neurosci 30:285-292.

Kempermann G, Jessberger S, Steiner B, Kronenberg G (2004) Milestones of neuronal development in the adult hippocampus. Trends Neurosci 27:447-452.

Khanna R, Li Q, Bewersdorf J, Stanley EF (2007) The presynaptic CaV2.2 channel-transmitter release site core complex. Eur J Neurosci 26:547-559.

Kreibich TA, Chalasani SH, Raper JA (2004) The neurotransmitter glutamate reduces axonal responsiveness to multiple repellents through the activation of metabotropic glutamate receptor 1. J Neurosci 24:7085-7095.

Lee EC, Yu D, Martinez de Velasco J, Tessarollo L, Swing DA, Court DL, Jenkins NA, Copeland NG (2001) A highly efficient Escherichia coli- 
based chromosome engineering system adapted for recombinogenic targeting and subcloning of BAC DNA. Genomics 73:56-65.

Leitzell K (2007) Synaptotagmin: is 2 better than 1? J Neurosci 27:4231-4232.

Li G, Pleasure SJ (2005) Morphogenesis of the dentate gyrus: what we are learning from mouse mutants. Dev Neurosci 27:93-99.

Lieberam I, Agalliu D, Nagasawa T, Ericson J, Jessell TM (2005) A Cxcl12CXCR4 chemokine signaling pathway defines the initial trajectory of mammalian motor axons. Neuron 47:667-679.

Lu M, Grove EA, Miller RJ (2002) Abnormal development of the hippocampal dentate gyrus in mice lacking the CXCR4 chemokine receptor. Proc Natl Acad Sci USA 99:7090-7095.

Miller JT, Bartley JH, Wimborne HJ, Walker AL, Hess DC, Hill WD, Carroll JE (2005) The neuroblast and angioblast chemotaxic factor SDF-1 (CXCL12) expression is briefly up regulated by reactive astrocytes in brain following neonatal hypoxic-ischemic injury. BMC Neurosci 6:63.

Nusser Z, Mody I (2002) Selective modulation of tonic and phasic inhibitions in dentate gyrus granule cells. J Neurophysiol 87:2624-2628.

Ohab JJ, Fleming S, Blesch A, Carmichael ST (2006) A neurovascular niche for neurogenesis after stroke. J Neurosci 26:13007-13016.

Øynebråten I, Bakke O, Brandtzaeg P, Johansen FE, Haraldsen G (2004) Rapid chemokine secretion from endothelial cells originates from 2 distinct compartments. Blood 104:314-320.

Palmer TD, Willhoite AR, Gage FH (2000) Vascular niche for adult hippocampal neurogenesis. J Comp Neurol 425:479-494.

Parachikova A, Cotman CW (2007) Reduced CXCL12/CXCR4 results in impaired learning and is downregulated in a mouse model of Alzheimer disease. Neurobiol Dis 28:143-153.

Pujol F, Kitabgi P, Boudin H (2005) The chemokine SDF-1 differentially regulates axonal elongation and branching in hippocampal neurons. J Cell Sci 118:1071-1080.

Represa A, Ben-Ari Y (2005) Trophic actions of GABA on neuronal development. Trends Neurosci 28:278-283.

Rostène W, Kitabgi P, Parsadaniantz SM (2007) Chemokines: a new class of neuromodulator? Nat Rev Neurosci 8:895-903.

Scharfman HE, Hen R (2007) Neuroscience. Is more neurogenesis always better? Science 315:336-338.

Schoch S, Gundelfinger ED (2006) Molecular organization of the presynaptic active zone. Cell Tissue Res 326:379-391.
Seri B, García-Verdugo JM, Collado-Morente L, McEwen BS, Alvarez-Buylla A (2004) Cell types, lineage, and architecture of the germinal zone in the adult dentate gyrus. J Comp Neurol 478:359-378.

Shakiryanova D, Tully A, Levitan ES (2006) Activity-dependent synaptic capture of transiting peptidergic vesicles. Nat Neurosci 9:896-900.

Sohur US, Emsley JG, Mitchell BD, Macklis JD (2006) Adult neurogenesis and cellular brain repair with neural progenitors, precursors and stem cells. Philos Trans R Soc Lond B Biol Sci 361:1477-1497.

Song M, Messing RO (2005) Protein kinase $C$ regulation of $\mathrm{GABA}_{\mathrm{A}}$ receptors. Cell Mol Life Sci 62:119-127.

Steiner B, Klempin F, Wang L, Kott M, Kettenmann H, Kempermann G (2006) Type-2 cells as link between glial and neuronal lineage in adult hippocampal neurogenesis. Glia 54:805-814.

Stumm RK, Rummel J, Junker V, Culmsee C, Pfeiffer M, Krieglstein J, Höllt V, Schulz S (2002) A dual role for the SDF-1/CXCR4 chemokine receptor system in adult brain: isoform-selective regulation of SDF-1 expression modulates CXCR4-dependent neuronal plasticity and cerebral leukocyte recruitment after focal ischemia. J Neurosci 22:5865-5878.

Sugiyama T, Kohara H, Noda M, Nagasawa T (2006) Maintenance of the hematopoietic stem cell pool by CXCL12-CXCR4 chemokine signaling in bone marrow stromal cell niches. Immunity 25:977-988.

Tozuka Y, Fukuda S, Namba T, Seki T, Hisatsune T (2005) GABAergic excitation promotes neuronal differentiation in adult hippocampal progenitor cells. Neuron 47:803-815.

Tran PB, Miller RJ (2003) Chemokine receptors: signposts to brain development and disease. Nat Rev Neurosci 4:444-455.

Tran PB, Banisadr G, Ren D, Chenn A, Miller RJ (2007) Chemokine receptor expression by neural progenitor cells in neurogenic regions of mouse brain. J Comp Neurol 500:1007-1033.

Wang LP, Kempermann G, Kettenmann H (2005) A subpopulation of precursor cells in the mouse dentate gyrus receives synaptic GABAergic input. Mol Cell Neurosci 29:181-189.

Zhao C, Teng EM, Summers Jr RG, Ming GL, Gage FH (2006) Distinct morphological stages of dentate granule neuron maturation in the adult mouse hippocampus. J Neurosci 26:3-11.

Zou YR, Kottmann AH, Kuroda M, Taniuchi I, Littman DR (1998) Function of the chemokine receptor CXCR4 in haematopoiesis and in cerebellar development. Nature 393:595-599. 